\title{
ESPAÇO E GÊNERO NA COMPREENSÃO DO PROCESSO SAÚDE-DOENÇA DA MULHER BRASILEIRA*
}

Rosa Maria Godoy Serpa da Fonseca* *

FONSECA, R.M.G.S.da. Espaço e gênero na compreensão do processo saúde-doença da mulher brasileira. Rev.latino-am.enfermagem, Ribeirão Preto, v. 5, n. 1, p. 5-13, janeiro 1997.

Trata-se de um ensaio onde é abordada a questão da determinação social do processo saúde-doença da mulher (através da sua inserção em classes sociais e da condição de gênero), articulada à noção de espaço social e historicamente construído, dada pela geografia crítica. As reflexões são ilustradas com dados de um estudo sobre determinação social do perfil reprodutivo de mulheres atendidas em unidades básicas de saúde de uni município da Região Metropolitana de são Paulo.

UNITERMOS: gênero, mulher, processo saúde-doença, geografia crítica, espaço

\section{A QUESTÃO DO PARADIGMA NO ESTUDO DOS FENOOMENOS SOCIAIS}

A compreensão dos fenômenos sociais se dá segundo referenciais teóricos que correspondem às visões de mundo que coexistem na sociedade. $O$ processo saúde-doença, enquanto manifestação fenomênica do mundo social não escapa a este processo de interpretação, ou seja, para examiná-lo é necessário a adoção de um determinado referencial filosófico que, por sua vez, não é atemporal, mas expressão do pensamento de uma época.

O principal compromisso social da ciência é a produção de teorias interpretativas do real, sendo, neste sentido importante que questione o saber existente para poder ultrapassá-lo, produzindo novas visões que serão sempre inacabadas e superáveis como condição de existência. Neste sentido, enquanto guia para a elaboração de conceitos, teoria e modelos, o paradigma expressa uma concepção teórica social e historicamente determinada.

"O problema está exatamente na identificação do paradigma novo que vai, assim, condenar ao olvido o velho paradigma e obrigar todo o aparelho a uma renovação. Esta questão não pode ser resolvida fora da História: é da observação dos fatos concretos, na forma como eles se apresentam. concretamente, que se impõe aos diversos especialistas um novo elenco de relações, dispostas sistematicamente e cuja força para deslocar as teorias precedentemente vigentes vem do fato de que o novo sistema de idéias é tirado da própria realidade e não de uma filosofia qualquer. (SANTOS, 1990, p. 157)

Ainda é importante ressaltar que o paradigma afeta todas as ciências impondo-lhes transformações radicais. A este respeito, comenta SANTOS:

\begin{abstract}
"Não nos deixemos enganar. Não é possível pensar em um paradigma que seja particular, exclusivo de uma ciência isolada, particular. Um paradigma afeta ao mesmo tempo todas as disciplinas científicas, exatas' ou não. Se é de fato que a cada aparição de um novo paradigma, a ordem de importância das ciências também muda, isso não quer dizer que há departamentos do saber que escapem à sua ação revolucionária. $O$ paradigma novo se impõe a todas as ciências e thes impõe transformações consideráveis e às vezes brutais". (SANTOS, 1990, p. 159).
\end{abstract}

\footnotetext{
* Trabalho apresentado na mesa redonda "Geografia e gênero na formação sócio-espacial contemporânea" do Encontro Internacional "Lugar, formação sócio-espacial-mundo" promovido pelo Departamento de Geografia da Faculdade de Filosofia, Letras e Ciências Humanas da Universidade de São Paulo. São Paulo, 8 a 10 de setembro de 1994

** Enfermeira. Professora Doutora do Departamento de Enfermagem em Saúde Coletiva da Escola de Enfermagem da Universidade de São Paulo. Vice-coordenadora do Núcleo de Estudos da Mulher e Relações Sociais de Gênero da Universidade de São Paulo (NEMGE)
} 
Neste ensaio, abordarei como o materialismo histórico e dialético embasa e ultrapassa a visão da ciência positiva da saúde-doença, articulada à concepção crítica de espaço geográfico. No que concerne à saúde-doença esta é a visão da epidemiologia social que concebe o processo saúdedoença como determinado pela maneira como a sociedade se organiza para a reprodução da vida social. Dado que esta vida ocorre num determinado espaço, a compreensão crítica deste é dada pela geografia crítica.

Ao se falar em "maneira como a sociedade produz a vida social" pretende-se incorporar a visão generificada que considera as desigualdades entre 0 feminino e o masculino neste processo. Várias correntes de pensamento tentam explicar estas desigualdades. Neste trabalho será abordada a do feminismo marxista, devidamente modificada para incorporar algumas considerações de outras teorias como do patriarcado, dado que somente a primeira não tem sido suficiente para explicar a não superação da subalternidade feminina na passagem das sociedades capitalistas para as socialistas.

Para se utilizar o referencial filosófico do materialismo histórico e dialético como marco teórico de interpretação é preciso entendê-lo como teoria do conhecimento que tem como meta não só interpretar como transformar a realidade, dado que reconhece 0 papel político do Homem enquanto agente social de transformação e não como mero receptor das influências sociais. Isto porque, para Marx, somente as idéias não transformam o mundo, é preciso que sejam submetidas à prática. Apenas quando se tornam forças materiais, ao levarem os homens à ação é que as idéias podem transformar o mundo. (MARX, 1985, p. 125)

Na sociedade primitiva, onde o pensamento do homem era dominado por representações mitológicoreligiosas, imputava-se às forças sobrenaturais os processos naturais, a ordem da vida social e o destino dos indivíduos. Esta visão prevaleceu até que a necessidade de um determinado tipo de conhecimento para subsidiar as transformações sociais encaminhou para uma interpretação racional dos fenômenos, desenvolvendo-se assim a ciência positivista, que subsidiou amplamente o desenvolvimento das ciências naturais e da tecnologia até nossos dias.

A ciência positiva nasceu numa época em que havia a necessidade de superação das contradições do feudalismo pelo capitalismo e permanece até nossos dias hegemonicamente no mundo ocidental em que a maioria das sociedades é organizada sob a égide deste modo de produção. (BENTON, 1988, p. 290-1)

É baseada no idealismo, que parte do princípio de que a consciência ou qualquer das suas manifestações como o pensamento, à vontade ou qualquer coisa de ideal e imaterial, é primário, fundamental e determinante. A matéria, a natureza, o mundo material, são produzidos por aqueles ou deles dependentes. Assim, a base de todos os objetos e fenômenos do mundo é uma certa substância ideal representada pela vontade divina, a razão mundial, a idéia absoluta ou o espírito. Em outras explicações, os objetos e fenômenos do mundo são derivados das sensações e percepções do homem e da sua razão. De qualquer forma, sendo de uma natureza ou de outra, a essência de todas as coisas está na consciência humana.

(HAHN, 1984, p. 25; BURLATSKI, 1987, p. 25)

Nesta visão, o homem é um ser ideal, existindo como entidade real na busca deste ideal. $E$ também universal, portador de uma essência, independentemente do local ou época em que vive. Como ser de existência possui uma essência ideal, pois foi criado baseado nesta essência; durante toda a sua vida deve buscar assemelhar-se o mais possível deste ideal. Existem padrões pré-determinados de pessoas humanas que devem servir de modelo para todos os demais. Esta teoria, concebida de diversas formas, apesar de reconhecer a complexidade do ser humano e a influência do meio social no desenvolvimento de suas potencialidades, coloca no indivíduo toda a responsabilidade disso.

Derivado daí há, igualmente, uma sociedade ideal, normalizada segundo valores universais de cooperação para o desenvolvimento das potencialidades humanas. A ordem social é mantida a partir do desempenho de diferentes papéis sociais que regulam o funcionamento da engrenagem social, sem conflitos ou contradições.

Com o desenvolvimento da sociedade capitalista e a agudização das contradições que lhe são inerentes verifica-se que a explicação dos fatos sociais baseados na ciência positiva, oriunda das ciências naturais, obtinha apenas uma visão parcial e dicotomizada da realidade, não permitindo a visualização do todo. Surge, então o materialismo histórico e dialético como uma proposta revolucionária para a superação desta visão tradicional, transformando o papel da filosofia que, de mera tradutora ou interpretadora dos processos sociais, passa a assumir um papel de orientadora para a ação, superando a visão explicativa anterior. (HAHN, 1984, p. 25)

Na visão do materialismo histórico e dialético, o mundo é, pela sua natureza, material, ou seja, existe fora da consciência humana e independente dela, não sendo produto nem do pensamento, nem de qualquer ser imaterial. Tudo o que existe é matéria, ou pelo menos, depende da matéria que é definida como a categoria filosófica que designa a realidade objetiva, que é dada ao homem nas suas sensações, que é copiada, fotografada, refletida pelas nossas sensações, existindo independentemente delas. (Lenin apud HAHN, 1984, p. 50; CHEPTULIN, 1982, p. 62)

Não apenas os corpos materiais com propriedades mecânicas são matéria, como também todas as formas 
qualitativamente diferentes deste mundo material, com suas propriedades físicas, químicas, biológicas e sociais, enfim, todas as coisas que têm a propriedade fundamental de existir, independentemente da consciência humana, e numa condição de constante desenvolvimento e transformação, segundo determinadas leis.

A partir disto, a sociedade, existindo fora da consciência humana e independentemente dela, também é material e o homem é um ser histórico, ou seja, determinado pelo espaço e época histórica em que vive. Assim, diferencia-se conforme sua inserção no tempo e no espaço. Como ser de existência, ele se faz, se constrói no seu próprio percurso histórico. E o único ser da espécie animal que consegue traçar a sua maneira de viver, sendo esta fruto de sua relação com os outros homens e com a natureza. Na concepção dialética, o homem é um ser de existência e a sua natureza se revela na medida em que ele se relaciona com 0 concreto. É a partir deste enfoque que surge o conceito de alienação como referindo-se à situação em que o homem não se percebe enquanto transformador da natureza e da sociedade em que vive. (CAMACHO, 1986, p. 10)

\section{ESPAÇO E FORMAÇÃO SÓCIO-ESPACIAL CONTEMPORÂNEA}

O espaço, enquanto suporte biológico dos grupos humanos e das suas atividades, é reconhecido pela geografia crítica como resultado da produção, historicamente determinado de acordo com a sucessão de modos de produção e onde o trabalho é a categoria central que explica as relações do homem com a natureza. (SANTOS, 1990, p. 167)

Dado que tudo ocorre sob as leis do desenvolvimento dialético, no processo de transformação da natureza, verificam-se transformações no próprio espaço, em função das transformações ocorridas nas necessidades do homem. Isto porque conforme muda a vida humana, impõem-se novas demandas em relação ao que o homem necessita para sobreviver. Desta maneira, não se pode falar em necessidades desvinculadas do contexto social e do momento histórico considerado. Além do espaço, assume importância a categoria tempo, dado que cada atividade humana muda conforme mudam historicamente, os tipos de produção. (SANTOS, 1990, p. 162)

"Produzir e produzir espaço são dois atos indissociáveis. Pela produção o homem modifica a Natureza Primeira, a natureza bruta, a natureza natural, socializando, desta forma, aquilo que Teilharde de Chardim chama de 'ecossistema selvagem'. É por essa forma que o espaço é criado como Natureza Segunda, natureza transformada, natureza social ou socializada. $O$ ato de produzir é, ao mesmo tempo, o ato de produzir espaço". (SANTOS, 1990, p. 163)

Quando os grupamentos humanos primitivos tiravam tudo o que necessitavam da Natureza, contida em um pequeno território, o faziam porque as suas necessidades encontravam-se circundadas apenas à sobrevivência. A medida em que a vida social foi adquirindo complexidade, tiveram que ser procuradas outras áreas geográficas que dessem conta da produção para $o$ atendimento às necessidades que por sua vez tornavam-se também cada vez gradativamente complexizadas, fazendo com que a noção de espaço também tivesse que ser reinterpretada. A noção de espaço parcial, ou seja, onde se concretizava cada formação social, foi necessário incorporar a noção de espaço global. Mudou também a idéia deformação social.

"A formação social se constitui numa unidade complexa de articulação de várias instâncias da organização social que pode conter vários modos de produção, entre os quais um é dominante e determina os outros (...) Pode ser entendida como a realidade que se forma processualmente na história, seja ela mais ou menos organizada ou institucionalizada, macro ou microssociológica. $O$ estudo de uma formação social inclui tanto as mudanças e transformações como as permanências e suas formas estruturais. É dentro do conceito abrangente deformação social que podemos analisar, numa determinada sociedade, o desenvolvimento das forças produtivas e as relações sociais de produção; as classes sociais básicas e a luta de classes; a divisão do trabalho; as formas de produção, circulação e consumo de bens; a população; as migrações; o Estado; o desenvolvimento da Sociedade Civil; as relações nacionais e internacionais de comércio, de produção e de dominação; as formas de consciência real e possível dos". diferentes grupos sociais e por fim o "modo de vida'..." (MINAYO, 1993, p. 67)

$\mathrm{Na}$ atualidade,

“... chegamos à fase histórica em que a noção de espaço global se impõe com mais força porque as variáveis que ajudam a tecer o seu contexto têm uma origem cada 
vez mais longínqua e um alcance mundial. Isto foi possível porque com o atual capitalismo da organização comandado pela presença de firmas multinacionais, o processo de acumulação de capital não poderia mais fazerse sem que os grandes produtores pudessem ir buscar, seja onde for, as condições para obtenção de um lucro cada vez maior". (SANTOS, 1990, p. 123)

O processo de mundialização da economia trouxe na sua esteira tanto a internacionalização do consumo como a internacionalização da produção, o que provocou a necessidade de redefinição do espaço das sociedades, antes circunscrito apenas ao lugar onde se dava localizadamente a vida social. Da mesma maneira, a produção do espaço deixa de ser conseqüência estrita da produção, assumindo importância fundamental o político enquanto esfera de manifestação dos conflitos sociais na luta pelo poder. (SANTOS, 1990, p. 124)

O processo de globalização da economia conseqüente à internacionalização do capital deu-se de uma maneira altamente desigual no espaço compreendido pelas diversas formações sociais. Segundo CHAUÍ, a conseqüência disto no Terceiro Mundo foi o colapso da modernização, que pode ser traduzido em alguns itens:

- o desemprego tornou-se estrutural, deixando de ser acidental ou expressão de uma crise conjuntural, porque o capitalismo opera muito mais por exclusão do que por inclusão dos sujeitos sociais no mercado de trabalho e de Consumo;

o centro do capitalismo tornou-se o capital financeiro, desvalorizando o trabalho e privilegiando o dinheiro;

- a terceirização tornou-se estrutural, deixando de ser um complemento da produção, operando por fragmentação e dispersão de todas as esferas da produção, com a compra de serviços do mundo inteiro;

- a ciência e a tecnologia deixaram de ser suporte do capital e converteram-se em forças produtivas e agentes de acumulação. Mudou a forma de inserção social dos técnicos e dos cientistas tornando-se agentes econômicos diretos e o conhecimento e a informação monopolizaram-se, fortalecendo os detentores do capital;

- a privatização também tornou-se estrutural com o capitalismo rejeitando e dispensando a presença estatal no mercado e nas políticas sociais;

- o centro econômico do capitalismo encontra-se em instituições internacionais como o Fundo Monetário Internacional (FMI) e Banco Mundial pelo processo de transnacionalização da economia que fez tornar desnecessário o estado nacional;

- a distinção entre países de Primeiro e Terceiro Mundo tende a ser substituída pela divisão do espaço em bolsões de sociedade e espaço processo saúde-doença dado que também é segundo os processos de pobreza absoluta e de extrema riqueza em cada país. Há, assim, um primeiro mundo e um terceiro mundo em cada país. A diferença está apenas no número de pessoas que pertence a cada um destes mundos, em função dos dispositivos legais de distribuição da renda e garantia de direitos sociais consolidados.

A autora concluiu que a este conjunto de condições corresponde um imaginário social que busca justificá-las como racionais, legitimá-las como corretas e dissimulá-las enquanto formas contemporâneas de exploração e dominação, sob a égide da ideologia neoliberal.(CHAUÍ, 1994, p. 6-8)

Sobre esta concepção constrói-se agora a visão do enquanto fenômeno social, determinado historicamente reprodutivos sociais.

No entanto, para que esta visão surgisse foi necessário ultrapassar várias outras visões de saúde e doença que prevaleceram no transcurso histórico da sociedade humana, correspondentes ao estágio de desenvolvimento das forças produtivas e das relações de produção em cada etapa histórica de desenvolvimento social.

\section{AS VISÕES DE MUNDO E O PROCESSO SAÚDE-DOENÇA}

$\mathrm{Na}$ evolução histórica das sociedades ocidentais podemos distinguir basicamente três teorias interpretativas deste fenômeno social.

A primeira e que esteve presente desde o início das sociedades ocidentais foi a TEORIA DA UNICAUSALIDADE que reconhece que a causa única e fundamental da doença situa-se fora do organismo humano acometido. Surgiu quando o homem não dispunha de meios para controlar a Natureza, e buscava as causas das doenças em fatores externos, geralmente de explicação metafísica, que entrando ou saindo do corpo humano por forças sobrenaturais, provocavam distúrbios quase sem qualquer controle pelo próprio homem.

Com o desenvolvimento das forças produtivas e a superação dos modos de produção que não propiciavam o desenvolvimento tecnológico, houve um grande avanço na explicação da causalidade das doenças através de microorganismos que, se não totalmente controlados pelos homens, materializavam as causas das doenças, constituindo-se em fatores fundamentais para o aparecimento das mesmas.

A teoria da unicausalidade teve um grande avanço na chamada "era bacteriológica" onde através da descoberta dos vários agentes etiológicos, principalmente 
relacionados às doenças transmissíveis, explicava 0 surgimento da doença. Neste modelo biologicista, o homem é considerado um ser cujas ações estão limitadas ao funcionamento mecânico dos órgãos e sobre o qual atuam processos biológicos ou físicoquímicos que desequilibram o sistema.

Esta teoria foi perdendo espaço gradativamente, pois a complexidade que foi adquirindo a organização social passou a gerar uma crescente necessidade de atenção à saúde que surtisse efeitos importantes na manutenção da qualidade da força de trabalho a serviço do capital. Ainda, no campo da saúde, a crescente sofisticação dos meios de diagnóstico e tratamento foi gradativamente reduzindo o acesso das pessoas a uma assistência à saúde compatível com as suas necessidades. Tudo isto fez com que se buscassem explicações para o processo saúde doença que subsidiassem uma busca de alternativas de assistência menos custosas, porém com impacto suficiente para garantir a força de trabalho. Por outro lado, os movimentos organizados da sociedade apontavam para outras causas de doenças que não apenas o agente etiológico. Isto propiciou a elaboração da teoria multicausal da doença.

A TEORIA DA MULTICAUSALIDADE surgiu nos finais do século passado, porém consolidou-se apenas neste, na década de 60 , substituindo a teoria unicausal. Coloca que no seu aparecimento da doença coexistem várias causas.

Estes fatores atuam como somatória de causas, sem que um seja mais importante que o outro. Desta maneira, o social é mais um fator no aparecimento da doença, tanto quanto a constituição psico-biológica do homem.

Uma variante deste modelo é a Teoria de Leavell e Clark, chamado modelo da tríade ecológica segundo a qual, as causas se ordenam dentro de três categorias possíveis ou conjunto de fatores que intervêm no aparecimento da doença: o agente, o hospedeiro e o meio. O comportamento anormal de um destes conjuntos de fatores pode ocasionar 0 desequilíbrio do sistema e conseqüentemente 0 aparecimento da doença. A presença de um ambiente desfavorável ocasiona transtornos no hospedeiro e ativação do agente que até então pode ter permanecido inativo ou em estado de não agressão, rompendo o equilíbrio.

Estes dois modelos anteriores, baseados no idealismo, têm se mostrado insuficiente para explicar o comportamento das doenças na sociedade, especialmente naquelas onde a condição social vigente baseia-se em grandes desigualdades. Contrapondo-se a elas e buscando uma explicação cuja lógica não resida em causas aparentes, mas na essência dos problemas, surgiu a TEORIA DA DETERMINAÇÃO SOCIAL DO PROCESSO SAÚDE DOENÇA.
Segundo esta teoria, baseada no materialismo histórico e dialético, a causa última do comportamento do processo saúde-doença deve ser buscada na forma segundo a qual a sociedade se organiza para a construção da vida social. Em primeiro lugar, esta teoria interpreta os fenômenos saúde e doença como expressões de um mesmo processo, evidenciando o seu duplo caráter: o biológico e o social, uma vez que encara que a natureza humana, apesar de ter um lastro biológico, se determina a partir da vida do homem em sociedade.

Assim, a organização social é o determinante fundamental deste processo e evidencia-se como manifestação da qualidade de vida dos diferentes sujeitos sociais que, por sua vez, é determinada pelos processos de reprodução social. A teoria da determinação social do processo saúde-doença permite compreender como cada sociedade cria um determinado padrão de desgaste em função do consumo e gasto de energia no processo de reprodução social. Nas sociedades classistas, especificamente naquelas organizadas sob o modo capitalista de produção, a cada classe social corresponde um determinado padrão de desgastes e potencialidades, manifestos através de condições negativas (riscos de adoecer ou morrer) ou positivas (possibilidades de sobrevivência).

O processo saúde-doença manifesta-se por meio de diferentes fenômenos cuja freqüência $e$ intensidade variam no tempo e no espaço e podem ser expressos nos níveis: individual ou singular; do grupo social cujo elemento de ligação dos seus componentes seja o trabalho (primordialmente da classe social); da estrutura social. Isto porque segundo BREILH, a compreensão da realidade social deve dar-se nas três dimensões que a compõem: o singular, o particular e o geral, sendo cada uma delas correspondente a uma totalidade parte da totalidade que compõe o social.

No primeiro nível (individual ou singular) o processo saúde-doença manifesta-se com variações na freqüência e na intensidade entre pessoas e pequenos grupos que se diferenciam entre si por atributos individuais tais como: sexo, idade, religião, escolaridade, rendimentos, etc. No segundo nível, entre classes sociais que compartilham das condições de vida e de trabalho, as manifestações se dão através de perfis de morbimortalidade peculiares de cada classe, como a expressão dinâmica da inserção destas classes no sistema produtivo. No nível da estrutura social, relativo a uma mesma formação social, o processo saúde-doença manifesta-se através de perfis de morbimortalidade peculiares desta sociedade em relação às demais. (BREILH \& GRANDA)

"Quando do ponto de vista marxista, abordamos a questão da saúde-doença assim como a medicina e as instituições médicas, 
esses fenômenos são colocados em relação com a totalidade social e com cada uma de suas instâncias dentro da especificidade histórica de sua manifestação. Saúde/Doença passam a ser tratada não como categorias ahistóricas mas como um processo fundamentado na base material da sua produção e com as características biológicas e culturais que se manifestam. São vistas como manifestação tanto nos indivíduos como no coletivo..."(MINAYO, 1993, p. 45)".

\section{CLASSE SOCIAL E GÊNERO NA EPIDEMIOLOGIA SOCIAL}

Conforme visto anteriormente, para a epidemiologia social a categoria chave para a compreensão do processo saúde-doença da população é a classe social, porque é capaz de expressar as diferenciações existentes na sociedade a partir da posição do sujeito social na produção da vida material. Isto, por sua vez, leva a um dado perfil de consumo, no qual adquire especial importância à relação dialética entre a base e a superestrutura social (locus privilegiado de formulação e veiculação da ideologia), como base para a compreensão das necessidades humanas, agora socialmente determinadas.

Ocorre que não apenas através da classe social pode-se determinar a posição do indivíduo na sociedade, senão que também através de outros atributos. Estes, muitas vezes relativos a especificidades da própria biologia que, por expressarem uma condição de desigualdade no espaço social, acabam também determinando o "lugar social" de cada um. Desta maneira, há outros recortes analíticos importantes dos quais se pode lançar mão para compreender os fenômenos sociais e, dentre eles, o próprio processo saúde-doença, tais como a raça! etnia, a geração e o gênero, objeto de reflexão neste trabalho.

A despeito de inicialmente, o gênero ter sido confundido com "papel sexual", por ater-se a uma visão funcionalista da sexualidade, atualmente, a concepção subjacente à visão materialista histórica e dialética é a que se refere ao sexo social e historicamente construído. (CASTRO, 1991, p. 25)

Embasado nisto, a definição de gênero implica em dois níveis, quais sejam, o gênero como elemento constitutivo das relações sociais, baseado nas diferenças perceptíveis entre os dois sexos e o gênero como forma básica de representar relações de poder em que as representações dominantes são apresentadas como naturais e inquestionáveis. (SCOTT, 1990, p. 34)

Ao assumir gênero como uma construção sociológica, político-cultural do termo sexo, CASTRO, chama a atenção para:

a) que o sexo não seja visto uma variável demográfica, biológica ou natural, mas que integre toda uma carga cultural e ideológica. Baseado na acepção de BEAUVOIR (1980), "ninguém nasce mulher; mas se faz mulher", a autora afirma a indicação implícita para a necessidade de referências concretas sobre a identidade masculina e a feminina;

b) a impossibilidade da compreensão do específico da identidade feminina, da posição da mulher na sociedade, da valorização ou desvalorização de seu trabalho, das divisões sexuais do trabalho/poder/exercício do erótico sem a compreensão do específico da identidade masculina e do que já de comum ao humano, já que o homem e a mulher são construções de gênero no humano;

c) o gênero como realização cultural através de ideologias que tomam formas específicas em cada momento histórico. Ainda, afirma que tais formas estão associadas a apropriações político-econômicas do cultural que se dão como totalidades, em lugares e períodos determinados. (CASTRO, 1991, p. 26)

Este enfoque rompe com a visão de que as discriminações contra as mulheres se produzem pela perversidade natural dos homens, recolocando-a num sistema de relações que se "perpetua porque serve a interesses, ainda que não tenham sido diretamente engendrados para este fim". (CASTRO, 1991, p. 26)

Em síntese, pode-se dizer que a categoria gênero pressupõe a compreensão das relações que se estabelecem entre os sexos na sociedade, diferenciando o sexo biológico do sexo social. Enquanto o primeiro refere-se às diferenças anátomo-fisíológicas, portanto, biológicas, existentes entre os homens e as mulheres, o segundo diz respeito à maneira que estas diferenças assumem nas diferentes sociedades, no transcorrer da história.

O sexo social e historicamente construído é produto das relações sociais entre homens e mulheres e deve ser entendido como elemento constitutivo destas mesmas relações nas quais as diferenças são apresentadas como naturais e inquestionáveis. Ao contrário, a análise mais profunda de tais relações revela condições extremamente desiguais de exercício de poder, aonde as mulheres vêm ocupando posições subalternas e secundárias em relação aos homens. A utilização da categoria gênero pretende assim explicar, à luz destas relações de poder, as manifestações fenomênicas sociais das mulheres, entre elas, o processo saúde-doença.

Desta maneira, a incorporação desta categoria analítica na epidemiologia social é fundamental para a compreensão das desigualdades sociais e da qualidade que assume o processo saúde-doença em cada sujeito ou 
em cada grupo social. Em se tratando de mulheres, além do conhecimento das especificidades da biologia feminina, há que se conhecer e compreender as especificidades da condição da mulher no espaço social considerado. Não basta dizer e reconhecer a situação de subalternidade feminina no mundo contemporâneo. Há que se conhecer as formas assumidas por esta subalternidade e como ela se expressa no que toca à determinação do processo saúde-doença. Isto pode ser feito através de algumas sub-categorias que concretizam as desigualdades existentes entre os sexos histórica e socialmente construídos.

Uma das sub-categorias importantes, por exemplo, é o perfil reprodutivo biológico, dada a importância que tem assumido o controle do corpo feminino (inclusive sendo "causa" do aparecimento de manifestação de doença) para a contenção populacional no Terceiro Mundo, especialmente das populações das classes sociais subalternas. Em relação a isto, é importante frisar que a visão mais ampla e aprofundada é dada quando se utiliza concomitantemente as categorias gênero e classe social, para a compreensão da dupla subalternidade da maioria das mulheres nas sociedades onde é mais evidente o "colapso da modernização", considerando-se que este opera muito mais por exclusão que por inclusão social e que este processo penaliza muito mais as mulheres.

\section{GÊNERO E PROCESSO SAÚDE-DOENÇA NA FORMAÇÃO SÓCIO ESPACIAL BRASILEIRA CONTEMPORÂNEA}

Para finalizar, gostaria de exemplificar como a epidemiologia social, agora reconstruída sob a noção da determinação social do processo saúde-doença (a partir da geografia crítica e do feminismo), reconhecendo que esta determinação se dá minimamente através da inserção de um sujeito portado de um sexo socialmente determinado, em uma dada classe social, pode compreender o processo saúde-doença da mulher no espaço socialmente construído da formação social brasileira contemporânea.

Isto será feito através da sub-categoria perfil reprodutivo biológico, no que concerne aos efeitos danosos do uso indiscriminados de métodos anticoncepcionais por mulheres das classes sociais subalternas, no espaço de um Município da Região Metropolitana de São Paulo no ano de 1989. (FONSECA, 1990)

Este Município é um espaço social construído a partir de uma economia primordialmente centrada no setor terciário como suporte para a industrialização que é muito grande na Região, determinada pela forma como se deu a implementação e a consolidação do capitalismo brasileiro, francamente dependente do capitalismo central.

É composto por uma população majoritariamente inserida no proletariado onde a condição de subalternidade feminina é evidenciada através da assunção de papeis muito claramente estabelecidos, relacionados ao cuidado dos filhos e o trabalho doméstico, mesmo quando a mulher assume uma parte da subsistência familiar através do trabalho remunerado.

Há que se lembrar que em relação à manutenção e reprodução da força de trabalho os princípios capitalistas visam a redução numérica das classes sociais subalternas para manter o exercício de reserva dentro de limites que não atendem contra a ordem social estabelecida. Esta contenção se faz, principalmente através do controle da sexualidade e da fecundidade feminina, por ser este corpo secundariamente valorizado na sociedade ocidental, historicamente androcêntrica e patriarcal. A valorização do masculino em detrimento do feminino estabelece uma hierarquia onde o homem é o chefe "natural" do grupo social (familiar), portador de um poder que lhe confere a primazia da decisão. Isto porque, como diz SAFFIOTTI:

“... o homem tem o poder apenas pelo fato de ser homem independentemente de suas capacidades. Este poder varia segundo sua inserção nas diferentes classes sociais, porém, existe sempre uma mulher com menos poder que o último dos homens". (SAFFIOTTI, 1994, p. 460)

Os dados da pesquisa revelam que aproximadamente $70 \%$ das mulheres entrevistadas utilizam alguma forma de controlar a sua fecundidade, sendo as mais utilizadas, os métodos de alta tecnologia e dentre eles, em primeiro lugar as pílulas anticoncepcionais, seguidas muito de perto pela esterilização.

Em primeiro lugar, o uso de métodos anticoncepcionais era predominantemente feminino (85\%) em conseqüência da ideologia androcêntrica e patriarcal dominante, explicitada anteriormente.

Em segundo lugar e diretamente relacionada à ideologia capitalista de reprodução da força de trabalho, apesar dos níveis de efeito colaterais das pílulas anticoncepcionais admitidos cientificamente situarem-se em níveis muito baixos e de pouca gravidade (ao redor de $30 \%$ para efeitos passageiros como náuseas e mal estar), aproximadamente $90 \%$ das mulheres queixavam-se de algum deles, incluindo-se aí desde manifestações leves como dores de cabeça, náuseas e mal estar, até alterações da libido e amenorréia. Estas alterações, em geral, eram consideradas pouco relevantes no espaço institucional dos serviços de saúde e contornadas através da troca do tipo de pílulas ou pela recomendação e 
encaminhamento para esterilização, especialmente quando a mulher já tinha dois ou mais filhos.

No entanto, nada chocou mais que constatar os casos de mulheres que foram submetidas ao uso de anticoncepcionais ou esterilização sem o seu próprio conhecimento, como explicitação máxima da escala dos valores capitalistas periférico-dependentes, androcêntricos e patriarcais. No mesmo estudo relatado, numa amostra de 159 mulheres, havia 3 que haviam sido esterilizadas sem conhecimento prévio, por iniciativa do marido ou do médico durante partos por cesárea e uma que tinha um DIU insertado no útero há aproximadamente seis anos, sem saber.

Com este pequeno exemplo, o que se quer concLuir é que isto ocorreu por se tratar de mulheres pertencentes às classes sociais mais desfavorecidas, cujo perfil reprodutivo biológico é determinado pela dupla condição de subalternidade, de classe e de gênero.

No entanto, estas desigualdades só são possíveis de constatação quando a observação do fenômeno se faz através de uma visão de mundo que comporte apreendê-las sob o olhar crítico que busca a causa última dos fenômenos na maneira como historicamente se produz a vida humana. Isto permite inclusive visualizar a transformação desta ordem das coisas a partir da ação humana, ou seja, através da práxis criativa e transformadora. Como cita MINAYO,

\footnotetext{
"É na práxis, na perspectiva dialética, que se dá a emancipação subjetiva e objetiva do homem e a destruição da opressão enquanto estrutura e transformação da consciência. Noutras palavras, a transformação das nossas idéias sobre a realidade e a transformação' da realidade caminham juntas" (MINAYO, 1993, p. 73)
}

\section{CONCLUSÃO}

A proposta da teoria da determinação social do processo saúde-doença, paradigma sobre o qual constróise a saúde coletiva, para a compreensão do processo saúde-doença da mulher, leva a que sejam visualizadas possibilidades de intervenção paradigmatizadas na concepção de que não basta fazê-lo com a finalidade de atender pontualmente queixas ou agravos, mas sim, com o horizonte de transformação efetiva da sua qualidade de vida, entendendo-se nela, as condições materiais do próprio espaço social. Enquanto prática social da área da saúde, a enfermagem historicamente tem priorizado cuidar do processo saúde-doença da população feminina, na medida em que isto tem sido privilegiado inclusive pelos organismos internacionais como a OMS (Organização Mundial da Saúde), o ICN (Internacional Council of Nurses), etc.

As considerações feitas nesse texto, resta-nos optar entre a prestação pontual de cuidados de enfermagem à população feminina ou contextualizá-la na proposta mais ampla de monitorá-la, intervindo nas formas de vida e trabalho da população, com vistas à transformação do seu processo saúde-doença. É óbvio que tal proposta deve ser multidisciplinar, pois foge completamente às possibilidades de apenas um único campo de práticas levá-la a cabo. No entanto, a condição "sine qua non" para isto é mais que mudar intenções, tratar de mudar a nossa forma de ver o mundo, de ver-nos a nós mesmas, enquanto mulheres e de ver a enfermagem enquanto prática social privilegiada para, no conjunto das práticas em saúde, transformar a saúde da mulher brasileira.

\section{SPACE AND GENDER UNDERSTANDING BRAZILIAN WOMAN'S HEALTH-ILLNESS PROCESS}

The author deals with the social determination of the woman's health-illness process (through her social class and gender) linking it to the concept of social space, historically constructed, based on critical geography. The considerations made are illustrated with data collected iii a study about the reproductive profile of woman who are assisted in public health units of the municipality of São Paulo.

KEY WORDS: woman, health-illness process, critical geography, space

\section{ESPACIO Y GÉNERO EN LA COMPRENSIÓN DEL PROCESO SALUD ENFERMEDAD}

Se trata de un ensayo donde se aborda la cuestión de la determinación del proceso salud-enfermedad de la mujer (a través de su inserción de las clases sociales v de la condición de género), articulada a la, noción de espacio social históricamente construido, dado por la geografía crítica. Las reflexiones son ilustradas con datos de un estudio sobre determinación social del perfil reproductivo de mujeres atendidas en unidades básicas de salud de un municipio de la región metropolitana de São Paulo. 


\section{REFERÊNCIAS BIBLIOGRÁFICAS}

01. BEAUVOIR, 5. O segundo sexo. São Paulo: Nova Fronteira, 1989. 2v.

02. BENTON, Positivismo. In: BOTTOMORE, T. Dicionário do pensamento marxista. Rio de Janeiro, Jorge Zahar, 1988. p. 290-291.

03. BREILH, J.; GRANDA, E. Investigação da saúde na sociedade: guia pedagógico sobre um novo enfoque do método epidemiológico. São Paulo: Cortezl ABRASCO, 1991. 115p.

04. BURLATSKI, F. Fundamentos da filosofia marxista-leninista. Moscou: Progresso, 1987. 392 p.

05. CAMACHO, J.S. A educação e suas linhas filosóficas - uma reflexão para as profissões de saúde. São Paulo: Escola de Enfermagem da USP, 1986. /mimeografado/

06. CASTRO, M.G. A dinâmica entre classe e gênero na América Latina: apontamentos para uma teoria regional sobre gênero. In: INSTITUTO BRASILEIRO DE ADMINISTRAÇÃO MUNICIPAL, RIO DE JANEIRO. Mulher e Políticas Públicas. Rio de Janeiro: IBAM/ UNICEF, 1991. p.39-69.

07. CHAUI, M. De alianças, atrasos e intelectuais. Folha de São Paulo, Caderno Mais, 24/04/ 1994. p.6-8

08. CHEPTULIN, A. A dialética materialista: categorias e leis fundamentais da dialética. São Paulo: Alfa-Omega, 1982. 354 p.
09. FONSECA, R. M. G. S. da. Mulher, reprodução biológica e classe social: a compreensão do nexo coesivo através do estudo dialético do perfil reprodutivo biológico de mulheres atendidas nas unidades básicas de saúde. São Paulo, 1990. 336p. Tese (Doutorado) Escola de Enfermagem, Universidade de São Paulo.

10. HAHN, E. ; KOSLNG, A. A filosofia marxistaleninista: curso básico. Lisboa: Avante, 1984. 260p.

11. MARX, K. O capital. 2. cd. São Paulo: Nova Cultural, 1985. 306p. v. 1.

12. MINAYO, M.C. O desafio do conhecimento: pesquisa qualitativa em saúde. São Paulo: HUCITEC, 1993. 269p.

13. SAFFIOTTI, H. Violência de gênero no Brasil atual. Estudos Feministas. v.2, n. 94. p.443461, 1994 (número especial)

14. SANTOS, M. Por uma geografia nova: da crítica da geografia à geografia crítica. São Paulo: HUCITEC, 1990.

15. SCOTT, J. El género: una categoría útil para el analisis historico. In: AMELANG, J.; NASH, M. Historia y género: las mujeres en la Europa moderna y contemporánea. Valencia: Ediciones Alfons El Magnanim, Institución Valenciana d'estudis y investigación, 1990. 